\title{
Commentary
}

\section{Soluble CD 163: A novel biomarker}

\section{Rajeev B. Ahuja}

Department of Burns, Plastic, Maxillofacial, and Microvascular Surgery, Lok Nayak Hospital and associated Maulana Azad Medical College, New Delhi, India

Address for correspondence: Dr. Rajeev B. Ahuja, Secretary, International Society for Burn Injuries and Head, Department of Burns, Plastic, Maxillofacial, and Microvascular Surgery, Lok Nayak Hospital and associated Maulana Azad Medical College, New Delhi - 110002, India.

E-mail: rbahuja@gmail.com

\section{INTRODUCTION}

here is an unending quest to diagnose early sepsis for a favorable outcome. Clinicians treating patients with sepsis are in need of better diagnostic and prognostic

\begin{tabular}{|l|l|}
\multicolumn{2}{|c|}{ Access this article online } \\
\hline Quick Response Code: & Website: \\
\hline & www.ijps.org \\
\cline { 2 - 2 } & Dol: \\
\hline
\end{tabular}

markers, and new knowledge in the immunopathogenesis of severe infections and sepsis will have the potential to generate new options for diagnosis and treatment of these patients. ${ }^{[1]}$ As some reports indicate, ${ }^{[2,3]}$ studying genetic predispositions may even help in identifying the susceptibility to sepsis, its prognosis, and potential for therapy.

Sepsis, from any source (burns or otherwise), triggers a cascade of responses and inflammatory reactions, generating 'markers,' which lend themselves to estimation, to aid in diagnosis, prognosis, and therapeutic responses. The simplest of these being the leukocyte count, neutrophil ratio, and blood culture. These simple, rapid tests require 
no special laboratory facilities and provide a valuable adjunct in the early detection of sepsis ${ }^{[4]}$. The combination of leukopenia and an elevated band / total neutrophil ratio seems to be particularly predictive of sepsis. ${ }^{[4]}$

In last few decades, several pro- and anti-inflammatory markers have been suggested to be elevated in sepsis. Some of the currently employed tests include measuring procalcitonin, lipopolysaccharide (LPS)-binding protein, C-reactive protein, interleukin (IL)-6, IL-10, and so on, as also early onset cytokines, (TNF)- $\alpha$ and interleukin (IL)-1. Procalcitonin (PCT) is a protein that has been proposed as a sensitive and specific marker of bacterial infection and sepsis. ${ }^{[5]}$ Soluble CD163 is considered to be a marker of alternatively activated (anti-inflammatory) macrophages. [6] Thus, it is a macrophage-specific marker in patients with disorders of inappropriate macrophage activation..$^{[7]}$ Its values may be elevated in conditions as wide ranging as coronary atherosclerosis, ${ }^{[8]}$ Gaucher's disease, ${ }^{[9,10]}$ myeloid leukemia, ${ }^{[10]}$ idiopathic arthritis, ${ }^{[11]}$ and sickle cell anemia ${ }^{[12]}$ to bacteremia. ${ }^{[13]}$ Investigators have emphasized the potential role of sCD163 as a diagnostic parameter in hematological and inflammatory diseases..$^{[9,10]}$ Therefore, sCD 163 is an extremely non-specific marker. In fact, one study even reported, “....... moderate elevation of sCD163 was observed only in patients with severe sepsis and / or bacteremia. Soluble CD163 did not discriminate between infected and non-infected patients". ${ }^{[14]}$

\section{STUDY DESIGN AND PATIENTS}

As sCD 163 is a non-specific marker, very strict inclusion and exclusion criteria would be warranted in a study evaluating its role in the susceptibility to sepsis. I would have expected patients with a history of coronary disease and arthritis to be part of the exclusion criteria, and so also patients > 75 years of age, as SCD 163 levels are low in the elderly (mentioned by the authors under 'Discussion'). Patients in the current study have ages in the range of 31 to 80 years.

Although not mentioned in the text, it seems from Table 1 that 4 / 18 patients died during or after the study, and from Table 4 it can be construed that one patient died within 12 hours of admission (because the leukocyte count was reflective of 17 patients after the initial 12 hours and no other reason is assigned). However, regardless of the total number of patients being 17 or 18 , what is surprising is that the authors reported a statistical significance of their findings with such a small number of patients, which got further reduced after their allocation to groups, for comparison. It seems the power of this statistical significance would be quite low, therefore, the authors have recommended a study with a larger number of patients, in spite of their results.

\section{RESULTS}

There is a gross difference in the levels of sCD 163 observed by the authors in normal healthy donors and the study patients, when compared with previous publications. Their normal mean serum values $150 \mathrm{ng} / \mathrm{ml}$ (range 50 - $300 \mathrm{ng}$ / $\mathrm{ml}$ ) are far lower than the median and range values reported by Gaïni S et al.; ${ }^{[14]} 2.99 \mathrm{mg} / \mathrm{l}(1.22$ - 12.65) for non-infected patients (mean value being equivalent to $2990 \mathrm{ng} / \mathrm{ml}$ ). In another article by Gaïni $\mathrm{S}$ et al. ${ }^{[1]}$ the normal mean values were $1.9 \mathrm{mg} / \mathrm{l}$ (or $1900 \mathrm{ng} / \mathrm{ml}$ ). In fact, the highest value of sCD163 recorded by the authors in infected patients, was $8531 \mathrm{ng} / \mathrm{ml}$, which is well within the normal range $(1.22-12.65 \mathrm{mg} / \mathrm{l})$ quoted by Gaïni S et al.. ${ }^{[14]}$ The authors acknowledge this discrepancy, but their results throw significant posers in the interpretation.

What value of SCD 163 should we attribute as significant to indicate sepsis or susceptibility to sepsis, or the levels that would indicate the patient will eventually go on to develop organ failure? Is there a mild, moderate, and severe elevation level of SCD 163, which may point toward infection? If there is a wide range of normal values and non-specificity of the marker, how much change in value from the admission level would be a significant indicator of sepsis or susceptibility to sepsis?

The authors report that sepsis, as defined by the ACCP / SCCM criteria, ${ }^{[15]}$ developed in $6 / 18$ patients during the period of study (120 hours, i.e., within five days of admission) and the sCD 163 levels were significantly higher in these patients compared to patients without evidence of sepsis. It is intriguing that in spite of diagnostic bronchoscopy (to rule out inhalation injury), excisional surgery, and wound cover with Euroskin ${ }^{\circledR}$, on all patients, sepsis should develop so rapidly! It is mentioned in the results that a significantly lower level of SCD 163 was observed in the septic group 12 hours after injury, when Figure 5 shows otherwise. Also, what makes the interpretation more difficult is that Figure 5 shows that the mean SCD163 values are actually higher in the non-sepsis group at 48 hours of observation! Actually, I would interpret this Figure to show that the mean SCD 163 level at 48 hours is $<24$ hours, is $<12$ hours, and is $<$ at admission, in the sepsis group.

Indian Journal of Plastic Surgery January-April 2011 Vol 44 Issue 1 
I would have also liked to know from this study, how many patients with high SCD 163 levels did not show any evidence of sepsis or organ failure and belonged to $<25 \%$ total body surface area (TBSA) burns. Conversely, how many patients with sepsis, high Sepsis-related Organ Failure Assessment (SOFA) score, and $>25 \%$ TBSA burns had sCD 163 values in the lower range, as it would also have been very indicative of the predictability value of these levels?

I stop my comments short on the significance of the correlation demonstrated in the article between sCD163 levels at different time periods and other studied parameters, because, the mean values of SCD 163 over the studied period do not show any consistency of elevation / decrease to make any conclusive interpretation possible. However, what is redeeming to note is a linear correlation between the $\mathrm{SCD}$ 163 values and the leukocyte count. As a corollary from this study, the leukocyte count can continue as a simple test to diagnose SIRS or sepsis along with other parameters as mentioned in the ACCP / SCCM 1992 document. ${ }^{\mid 15]}$

I am a little surprised that the authors see a high potential in this marker to diagnose susceptibility to sepsis in burn patients, from their study.

\section{REFERENCES}

1. Gaïni S, Pedersen SS, Koldkaer OG, Pedersen C, Moestrup SK, Møller HJ. New immunological serum markers in bacteraemia: Anti-inflammatory soluble CD163, but not proinflammatory high mobility group-box 1 protein, is related to prognosis. Clin Exp Immunol 2008;151:423-31.

2. Fang XM, Schroder S, Hoeft A, Stuber F. Comparison of two polymorphisms of the interleukin-1 gene family: Interleukin-1 receptor antagonist polymorphism contributes to susceptibility to severe sepsis. Crit Care Med 1999;27:1330-4.

3. Holmes CL, Russell JA, Walley KR. Genetic Polymorphisms in Sepsis and Septic Shock-Role in Prognosis and Potential for
Therapy. Chest 2003;124:1103-15.

4. Alistair GS, Philip MB, Hewitt JR. Early diagnosis of neonatal sepsis. Pediatrics 1980;65:1036-41.

5. Assicot M, Gendrel D, Carsin H, Raymond J, Guilbaud J, Bohuon C. High serum procalcitonin concentrations in patients with sepsis and infection. Lancet 1993;341:515-8.

6. Moestrup SK, Moller HJ. CD163: A regulated hemoglobin scavenger receptor with a role in the anti-inflammatory response. Ann Med 2004;36:347-54.

7. Schaer DJ, Schleiffenbaum B, Kurrer M, Imhof A, Bächli E, Fehr J, et al.. Soluble hemoglobin-haptoglobin scavenger receptor CD163 as a lineage-specific marker in the reactive hemophagocytic syndrome. Eur J Haematol 2005;74:6-10.

8. Aristoteli LP, Møller HJ, Bailey B, Moestrup SK, Kritharides L. The monocytic lineage specific soluble CD163 is a plasma marker of coronary atherosclerosis. Atherosclerosis 2006;184:342-7.

9. Moller HJ, Aerts H, Gronbaek H, Peterslund NA, Hyltoft Petersen P, Hornung N, et al.. Soluble CD163: A marker molecule for monocyte/macrophage activity in disease. Scand J Clin Lab Invest Suppl 2002;237:29-33.

10. Moller HJ, de Fost M, Aerts H, Hollak C, Moestrup SK. Plasma level of the macrophage-derived soluble CD163 is increased and positively correlates with severity in Gaucher's disease. Eur J Haematol 2004;72:135-9.

11. Bleesing J, Prada A, Siegel DM, Villanueva J, Olson J, llowite NT, et al. The diagnostic significance of soluble CD163 and soluble interleukin-2 receptor alpha-chain in macrophage activation syndrome and untreated new-onset systemic juvenile idiopathic arthritis. Arthritis Rheum 2007;56:965-71.

12. Moller HJ, Nielsen MJ, Bartram J, Dick MC, Height SE, Moestrup SK, et al.. Soluble CD163 levels in children with sickle cell disease. Brit J Haematol 2011;153:105-10.

13. Moller HJ, Moestrup SK, Weis N, Wejse C, Nielsen, H, Pedersen $\mathrm{SS}$, et al.. Macrophage serum markers in pneumococcal bacteremia: Prediction of survival by soluble CD163. Crit Care Med 2006;34:2561-6.

14. Gaïni S, Koldkjaer OG, Pedersen SS, Pedersen C, Moestrup SK, Møller HJ. Soluble haemoglobin scavenger receptor (sCD163) in patients with suspected community-acquired infections. APMIS 2006;114:103-11.

15. ACCP/SCCM Consensus Conference Committee. Definition for sepsis and organ failure, and guidelines for the use of innovative therapies in sepsis. Crit Care Med 1992;2:864-74. 